\title{
El liberalismo a la conquista del amor. Algunas constataciones y reflexiones sobre el consumo sentimental y sexual de masa en la era de Internet
}

Pascal Lardellier*

\begin{abstract}
Resumen
Desde una decena de años, el aumento de los sitios de encuentro para los solteros han contribuido a tecnificar e "industrializar" las relaciones sentimental-sexuales. Este artículo demuestra que más ampliamente son los principios del liberalismo en tanto doctrina los cuales se han apoderado de variadas maneras de las relaciones amorosas, porque una nueva economía relacional, fundada sobre la efectividad, la intercambiabilidad, el rendimiento y la rentabilidad, prevalecen ampliamente sobre estos sitios de encuentro.

Palabras claves: Internet - sitios de encuentro - relaciones sentimental-sexuales - liberalismo - nueva economía relacional - valores y contravalores liberales.

Abtract

Since ten years, the increase of meeting websites for singles has helped to introduce technology and "industrialize" the emotional-sexual relationships. This paper shows that more widely the principles of liberalism as doctrine have taken over love relationships in a variety of ways, because a new relationship economy, based on effectiveness, interchangeability, performance and profitability, largely prevails over these meeting websites.
\end{abstract}

Keywords: Internet - meeting websites - emotional-sexual relationships - liberalism - new relationship economy - liberal values and counter-values.

* Profesor en la Universidad de Borgoña, Dijon, Francia. Investigador en el Laboratorio CIMEOS/3S. Director del Master 2 Research Comunication y Médiations. Director científico de Propedia, laboratorio del GrupolGS, París. Correo electrónico: pascal.lardellier@u-bourgogne.fr 


\section{A MODO DE INTRODUCCIÓN ${ }^{1}$}

Internet y los sitios de encuentro han metamorfoseado las relaciones amorosas en poco tiempo. Esta afirmación, que no es puramente determinista, se funda en una serie de constataciones. Después de una quincena de años, vemos aparecer nuevas modalidades de encuentro, el "flirteo" online y el enamorarse detrás de la pantalla. Las modalidades y la temporalidad tradicionales del encuentro amoroso se han alterado. En Internet se aprende a conocer "el interior" de las personas y a enamorarse de "desconocidos íntimos". En 1999, la película You' ve got a mail ${ }^{2}$ puso explícitamente en escena una historia e imágenes sobre este nuevo fenómeno.

Por otra parte, el actor americano John Malkovich, quien también es director, propuso en 2012 en París, en el teatro l'Atelier, una versión contemporánea de la célebre novela de Choderlos de Laclos, "Relaciones peligrosas"; pero Malkovich, que encarnó en 1989 al vizconde de Valmont para el realizador Stephan Frears, adaptó esta vez la obra clásica a la "generación de Internet". En su puesta en escena, las redes sociales (Facebook, Twitter...), los smartphones y los SMS juegan un rol principal. Se ama siempre como una época nos permite amar. Y una época es un conjunto de valores y de técnicas. La adaptación parisina de Malkovich muestra cuál es el lugar de lo escrito en las relaciones de seducción y amorosas que se efectúan en la era de Internet. De seguro hay todavía, como en la era clásica, cinismo, duplicidad, mentiras y manipulación, pero esta vez estas son tecnológicamente asistidas.

Más ampliamente, este es un nuevo estado del espíritu, y una ideología inédita que presidirá en lo sucesivo a las relaciones sentimental-sexuales asistidas por ordenador. Estas se "mercantilizan" y los solteros practican en Internet aquello que se podría denominar el "marketing amoroso".

En este texto analizaremos, primero, la manera como el liberalismo se impuso como la nueva ideología dominante en las relaciones sentimentales posmodernas. El liberalismo está presente, implícitamente, en los discursos de los internautas, así como en sus prácticas y en los "reflejos" relacionales adoptados cuando ellos están "en línea". Para esto, nos apoyaremos sobre investigaciones que hemos realizado sobre este tema en el espacio francófono desde hace ya diez años.

Enseguida propondremos, de forma más amplia, algunas reflexiones sociológicas y consideraciones filosóficas sobre el amor y la pareja en la era de las redes digitales.

\section{METODOLOGÍA DE INVESTIGACIÓN}

Concerniente a la metodología, precisamos que este texto se funda sobre los testimonios recibidos en dos investigaciones realizadas entre el 2003 y el 2012, y publicadas en 2004 y 2012 (Lardellier, 2004, 2012). Para realizar estas investigaciones nos asociamos a cuatro

Traducción del Dr. (c) Felipe Tello. Esta traducción se hizo con la expresa autorización del autor.

Tienes un e-mail en su versión para Latinoamérica (N. del T.). 
sitios de encuentro de finalidad sentimental-sexual de orientación heterosexual, que reúne público francés y francófono ${ }^{3}$. Estos son 260 (130 por 2) cuestionarios que fueron recibidos y tratados, y 30 entrevistas en profundidad. El tema de este texto, "el liberalismo conquista el amor", fue espontáneamente evocado y enunciado por la mayoría de las personas consultadas, con expresiones y formulaciones diferentes, pero convergentes.

Los análisis realizados a estos cuestionarios, por supuesto, se han ampliado con la lectura de autores que han trabajado este tema.

\section{EL LIBERALISMO A LA CONQUISTA DE LAS RELACIONES AMOROSAS}

Para comenzar, señalaremos que las relaciones amorosas producidas "en línea" conocen diferencias notables con aquellas de la vida real. En Internet no se ve al interlocutor, y no se le conoce, pues él/ella se encuentra escondido detrás de un "seudónimo" y de la pantalla. De la misma forma, las cosas suceden mucho más rápido que en la vida real, donde temporalidades más lentas dirigen la seducción.

De la misma forma, varios autores han remarcado estos últimos años la sumisión de las relaciones digitales al liberalismo, el cual es considerado a la vez como una doctrina económica, un conjunto de valores y una ideología. De hecho, con la web es posible considerar que las relaciones sociales se "mercantilizan", y que ellas funcionan según el principio de un utilitarismo desenfrenado. Este punto de vista cuenta con numerosos partidarios, porque señalar que esta doctrina económica se apodera de las relaciones es más que solo una metáfora. Así, tomar ciertas expresiones en sentido literal es revelador; los internautas que hemos interrogado evocan espontáneamente, a propósito de los sitios de encuentro: "la gran feria de corazones", un "supermercado", "el comercio y el negocio", "un consumo sexual desenfrenado" o una "vitrina para los solteros". Ellos son propensos a decir que eligieron un compañero "como escogerían un yogur, o un producto cualquiera, en su carro de supermercado". En resumen, ¡las personas tienen la impresión de convertirse en mercancía, una vez inscritos en un sitio de encuentro! Algunos decepcionados por estos sitios incluso mencionan la prostitución "porque se paga para tener relaciones con desconocidos"... Estas expresiones reenvían al comercio o al mercado, las cuales penetran la esfera de los encuentros amorosos. Así, estos clichés lexicales son enunciados por los mismos adeptos a los sitios de encuentro.

El encuentro amoroso ha devenido un mercado por completo, que "vende" a todos los solteros la posibilidad de relaciones sexuales rápidas, así como la esperanza de una vida de a dos. Era evidente que los empresarios, ayudados por los especialistas del marketing, harían su entrada en este nicho, casándose con los deseos y aspiraciones de los individuos, así como con las tendencias sociales más importantes.

3 Los sitios visitados con objeto de estas investigaciones fueron: Netclub, Amoureux.com, Attractive World y Points-communs.com. 
Es posible identificar en las redes digitales y en los sitios de encuentro lógicas sociológicas que existían previo a su aparición: la homophilia, esta tendencia a dirigirse hacia personas como nosotros mismos, y la endogamia, que produce parejas de categorías sociales, de valores y religión similares o próximos. De hecho, se reconocerá la importancia de "afinidades culturales", como principio de organización del mercado matrimonial, y por tanto, de la constitución de parejas. La elección puede parecer así aún más sorprendente "en línea", donde se comienza siempre a dialogar con personas anónimas. ¿El amor no será entonces tan ciego como pensamos?

Debemos, por otra parte, remarcar que el mercado francés del encuentro amoroso en línea ha conocido varios períodos importantes. Y luego de la primera etapa de sitios generalistas, se ha visto segmentarse a este mercado para proponer sitios comunitarios, los cuales se agrupan según criterios étnicos, religiosos, socioculturales y socioeconómicos.

Pero de la misma forma, sobre la red, las relaciones se encuentran liberalizadas. Porque todos los grandes principios de la economía de mercado están presentes: la abundancia de la oferta, la racionalización de la búsqueda amorosa, la focalización selectiva, el hecho de poder elegir permite una oferta abundante y la estandarización de los "productos" (Illouz, 2006). Aquí de hecho se completan hojas "antropométricas", donde se deben respetar estrictamente los criterios preestablecidos. Se induce a una "cosificación" generalizada. La inmensidad de la "oferta" -ide centenares de miles de fichas en línea!- implica una mercantilización, las fichas personales de los sujetos inscritos son analizadas como productos, luego de leer la ficha técnica se podrá "testear" y "cambiar" el producto, si el funcionamiento es insatisfactorio o defectuoso.

Por medio de todos los textos y de todas las imágenes intercambiadas entre desconocidos en los sitios de encuentro es donde el liberalismo invade la esfera de las relaciones humanas. En efecto, se debe ser eficiente y atractivo para ser "sacado del lote", y ser destacado. Se debe efectuar constantemente la mejor performance, por medio de las fotos subidas y las palabras enviadas. Y las relaciones amorosas se deben plegar a un imperativo de rendimiento, de eficiencia y de rentabilidad. Las "fichas personales" puestas en línea deben ser "vendedoras" e "impactantes" para ser destacadas. Y estos adjetivos, que son temas del marketing y del coaching, contaminan el espacio de la relación íntima. En los sitios de encuentro amoroso, cada uno practica el "marketing amoroso", y se considera a sí mismo como un "producto exclusivo" a promover, producido constantemente por miles de otros. De hecho, en los sitios de encuentro (como en las redes sociales), muchas personas practican, consciente o inconscientemente, el "personal branding". ¡Ellos deben ser su propia marca! ¡Y aquí una noción y un concepto que nuevamente nos reenvía al comercio!

Hay una célebre obra del teatro francés (de Pierre Marivaux, 1688-1768) que se titula Les jeux de l'amour et du hasard ${ }^{4}$. Sin embargo, en la actualidad, en los sitios de encuentro amoroso, es posible hablar de "los juegos del amor y del mercado", porque las relaciones

4 Los juegos del amor y del azar (N. del T.). 
tecnificadas implican un rendimiento y una rentabilidad, ya que cada internauta es su propio "cyber-agente matrimonial". En la era del marketing y del liberalismo triunfante, tenemos la impresión de que los sentimientos se pueden reducir a "ventajas para el cliente", en "capital emocional", en éxito en las entrevistas.

En un registro paralelo, los speed-dating simbolizan esta tendencia: el primer contacto amoroso se parece sospechosamente a una entrevista de trabajo. A una contratación profesional.

Y desde la aparición reciente del "coaching amoroso" los love coachs manejan a los solteros como si estos fueran cuadros superiores desclasados, a los cuales deben motivar para que puedan, de nuevo, obtener un supertrabajo. Valorizar su capital, expresar sus cualidades, explotar su potencial; tales son las misiones de estos "entrenadores relacionales" de nuevo género. Estos principios y estas prácticas pertenecen a la ideología de la gestión y se inscriben en la corriente liberal que se apodera de las relaciones, especialmente de las amorosas.

Seguramente hay romanticismo y sinceridad en las redes digitales, no solamente cinismo. Sin embargo, la mayoría de las personas inscritas en un sitio de encuentro están, ante todo, en la búsqueda de relaciones de rápido consumo. Según los testimonios de los adherentes, los miembros masculinos están en general muy prestos, ávidos de números de teléfono o de direcciones $W L M$ o de Skype personales; después de los encuentros $I R L^{5}$, buscan, lo más rápido posible, "concluir la relación", es decir, pasar a la relación sexual propiamente tal.

Varios libros, novelas y ensayos escritos estos últimos años por personas que frecuentan los sitios de encuentros confirman esta tendencia hacia "la industrialización de la conquista". En 2005, el francés Lewis Wingrowe explica en su obra Des souris et un homme ${ }^{6}$ cómo la racionalización, asociada con las herramientas informáticas, podría permitir un "rendimiento óptimo" en el proceso de seducción. Pero no solo hay ganadores en estos juegos del amor y del mercado. En su novela Extension du domaine de la lutte ${ }^{7}$ el célebre novelista francés Michel Houellbecq a partir de 1994, había presentido la entrada de la sexualidad en la era de la competición liberal, con winners y losers. Él presenta en esta obra un "antihéroe" frustrado, antipático y patético, torturado por pulsiones jamás satisfechas, las cuales le hacen sufrir cruelmente. Los "bellos" y los "seguros de ellos mismos" logran sus fines sexuales muy fácilmente. En tanto, a los perdedores solo les restan las imágenes, las fantasías y la masturbación como consuelo.

\section{EN LOS SITIOS DE ENCUENTROS, UN TRIPLE PRINCIPIO DE ECONOMÍA}

Para continuar en un registro económico, un triple principio de economía rige las relaciones amorosas en la web y asegura su éxito: economía de tiempo, economía de dinero y economía emocional. De tiempo, porque una vez inscrito, y en tan solo algunos

\footnotetext{
In the Real Life (N. del T.).

Ratones y un hombre (N. del T.).

Existe traducción al español: Ampliación del campo de batalla (Editorial Anagrama) (N. del T.).
} 
minutos, se tiene acceso a un "contenedor de solteros" inmenso, compuesto de miles de personas que nos interesan virtualmente y que pueden, en potencia, estar interesadas en el nuevo perfil.

Economía de dinero, de igual forma, porque entrar en contacto con todas estas personas, sería mucho más costoso (salidas, invitaciones de por medio) en la "vida real", sin Internet. Así, realizar un primer contacto gracias a la misma carta "cortar y pegar" y enviarla a una decena de personas, es una práctica corriente y que revela taylorismo, ipues se trata de racionalizar una tarea!

Por último, una "economía emocional" es ofrecida por estos sitios, porque la "pérdida de la cara" y los costos son oportunamente desplazados por la ausencia de un otro. Hacer un desaire digital no tiene ningún costo en términos de honor. De seguro, hay una violencia que no tiene nada de virtual y que puede provocar aquello que los psicoanalistas Ilaman una "herida narcisista", cuando la relación involucró una inversión afectiva. Para el resto "pasar a la siguiente" y ya.

Es el sistema de los sitios de encuentro en su conjunto el cual induce esta lógica de consumo. Hacer la elección más racional y pertinente, generar tráfico alrededor de su ficha a fin de llegar a ser el "producto-insignia", acumular los contactos... La lógica es la de un consumo sentimental y sexual masivo.

Ciertos adeptos a los sitios de encuentro se vanaglorian de coleccionar aventuras sexuales como si coleccionaran objetos insólitos o mariposas. Para ellos, gracias a los sitios de encuentros la conquista ha pasado de lo artesanal a lo industrial. Los sitios de encuentro amoroso consagran el matrimonio entre el consumo sexual y afectivo, y las técnicas del marketing. Nuestra época racionaliza la economía sentimental. Se habla aún del corazón, pero a menudo este es un "target del corazón", término usado por el marketing.

El concepto que simboliza esta mercantilización del encuentro amoroso online es el sitio francés AdopteUnMec. $\mathrm{Com}^{8}$. Con su espíritu feminista lúdico y relajado, este sitio permite a las mujeres caminar con un carro en los pasillos de un supermercado virtual que propone "hombres objeto". iEllos se convierten en "productos regionales que no pueden faltar" o "la promoción del día"! Los hombres, pasivos, tienen pocos derechos en este universo; ellos solamente deben obedecer.

La metáfora comercial anima este sitio; la usuaria todopoderosa puede construir su "mercado" por medio de una shopping list, la que ha preestablecido gracias a ciertos criterios. Este sitio exige una buena dosis de humor. Él ha ganado gran aceptación en una clientela joven, la que maneja perfectamente los códigos relacionales paródicos de las redes sociales. Aún nos encontramos en el registro del amor capturado por el liberalismo, aunque sea a título caricaturesco.

$8 \quad$ Adopta un hombre o adopta un muchacho (N. del T.). 


\section{LA RED SENTIMENTAL, UNA NUEVA “INTERNACIONAL DE LOS SOLTEROS”}

Pero el liberalismo se expresa de manera más concreta aun cuando se evoca el reencuentro amoroso en línea. Porque la expansión planetaria de los sitios de encuentro permite identificar, de manera más amplia, el nacimiento de una nueva "internacional de solteros". De este modo, decenas de miles de mujeres que habitan países en vías de desarrollo o en zonas afectadas por disturbios políticos buscan emigrar a un país "rico", gracias a los recursos de la web. Esta "cibermigración matrimonial" ha abierto flujos migratorios de un nuevo género, asegurando la fortuna de los propietarios de los cibercafés. En un documental titulado Nord-Sud.com, el francés François Ducat explica que en 1997 había cuatro cibercafés en la ciudad de Yaoundé, Camerún, y 450 en 2007. ¿Cuántos hay en el 2014? ¿Y cuántos de estos cibercafés en las capitales, en los pueblos y en las ciudades venden conexiones y "la esperanza de una vida mejor" en el exilio matrimonial?

Dos exigencias logísticas para estos cibercafés: que los ordenadores estén dentro de cubículos individuales cerrados (por una cortina, frecuentemente) y, sobre todo, equipados con webcams. Así, los hombres occidentales que chatean con estas mujeres desean "juzgar sus piezas". La competencia es ruda, solo las mujeres más "atractivas" serán consideradas. Estas mujeres deben ser a la vez jóvenes, dóciles, sensuales y "gentiles", listas a esperar que se les proponga un encuentro en Europa o en América del Norte. Esta "internacional de los solteros" ve cohortes de mujeres africanas, asiáticas o de expaíses comunistas intentar (y a veces lograr) una "ciberunión".

Esto necesariamente tendrá por consecuencia un desarraigo familiar y cultural. Ellas intentarán una nueva vida, lejos de sus casas, con un desconocido blanco (lo más frecuentemente), rico (para sus niveles de vida), y la mayor parte del tiempo (mucho) más viejo que ellas. Estos hombres "compran" la juventud de sus mujeres y les ofrecen por intercambio las "condiciones materiales de una vida mejor". Estas uniones tendrán éxito, o no. Algunas se adaptarán y "reconstruirán sus vidas" en Occidente; otras se deprimirán, pero harán todos los sacrificios por quedarse; por último, hay aquellas que volverán a sus países, después de constatar su imposibilidad para integrarse y decepcionadas de su "príncipe encantado occidental", que no era el hombre finalmente.

Es percibible la asimetría de estas relaciones y las expectativas económicas que las presiden, más allá de las justificaciones de los protagonistas y de la apelación a los "valores privilegiados" que cada uno de los esposos encarnaría, y de los cuales los nativos de sus respectivos países carecerían... Todo esto no debe ser visto con demasiado romanticismo. Porque este exilio conyugal ve también a veces familias desgarradas para recomponerse con otros, aleatorios, en el "El Dorado europeo o americano".

Si este fenómeno mundializado de la búsqueda amorosa participa en un gran melting-pot intercultural, desgarrando destinos y creando bellas historias, también podría provocar, si se amplifica, un verdadero desequilibrio de "balances conyugales internos":

"A largo plazo, la mundialización del mercado de encuentros podría tener consecuencias lamentables. Las mujeres occidentales ya tienen dificultades para encontrar hombres que 
estén a la altura de sus expectativas. En cuanto a los hombres, aunque seducidos por las mujeres dinámicas, las prefieren, sin embargo, a menudo no demasiado exigentes en la casa, para asegurarse una vida de pareja 'sin problema'. El riesgo es grande porque un número cada vez más importante de hombres se vuelve hacia el mercado internacional para 'comprar' la sumisión, la juventud y la belleza, dejando solas, en sus países, a mujeres diplomadas e independientes..., sin embargo, para los hombres pobres del Norte será aun cada vez más difícil casarse" (Kaufmann, 2010: 192).

La "internacional de los solteros" abierta por los sitios de encuentros está fundada, en principio, sobre intereses económicos. Los sentimientos no están ausentes, pero ellos vienen más tarde. Los "juegos del amor y del mercado" serán desde ahora en adelante mundializados.

\section{MÁS AMPLIAMENTE, A PROPÓSITO DEL AMOR EN INTERNET}

Ampliaremos ahora un poco el cuadro de nuestro análisis, a fin de proponer algunas consideraciones más generales, sociológicas y filosóficas, sobre las nuevas formas de la pareja y el amor en la era de Internet.

\subsection{Los solteros enfrentan tensiones paradójicas}

En primer lugar, la soledad jamás ha estado tan presente en nuestra sociedad como en esta época que nos propone una "oferta relacional" increíble y hace de la comunicación una virtud social. Los solteros inscritos en los sitios de encuentro coleccionan "toques digitales" y "besos virtuales", de centenares de personas que han visitado sus "fichas personales", sin que los encuentros, cuando tienen lugar, den lugar a relaciones duraderas. Por cierto, a veces esto ocurre, pero no siempre...

Estos solteros, cada día más numerosos, enfrentan una fuerte tensión cotidiana: prosperar, tener éxito, realizarse y, al mismo tiempo, darse los medios para "hacer pareja", porque la presión social y de su entorno ejerce con frecuencia sobre ellos, con fuerza, una exigencia implícita e insistente. Y si nuestra época valoriza a aquellos que comunican bien y se saben afirmar en sus relaciones, nunca las dificultades para encontrarse han sido tan grandes. Las millones de personas inscritas en los sitios de encuentro son un testimonio de ello.

\subsection{La pareja tradicional metamorfoseada por las TIC}

En todo caso, los internautas que "flirtean en línea" se encuentran confrontados a un modo de encuentro que, para comenzar, revierte la cronología de los eventos: se aprende a conocer al otro antes de encontrarse con él/ella, y se descubre "el interior" de las personas. Cuando estas se encuentran, la relación sexual viene muy rápidamente, si el feeling está presente. Y en seguida el amor vendrá (o no), y la pareja se construirá (quizás). Se comprende que este cambio "copernicano" en el proceso amoroso priva a los individuos de sus herramientas tradicionales. Así, ellos deben inventar un nuevo código relacional, inédito en la historia de las relaciones humanas y de los lazos amorosos. 
La net constituye una verdadera solución para encontrar "el alma gemela", pero con la condición de no quedar prisionero de mailles $d u$ fillet ${ }^{9}$. Se debe pasar frecuentemente al otro costado de la pantalla, recordando que en la Metamorfosis de Ovidio, Pygmalion mantenía una relación virtual (¡en aquella época ya!) con su bella estatua Galatea. De una ilusión a la otra, Narciso prefiere su imagen más que el tierno amor que le juró su musa Eco, así hasta ahogarse. ¿Y cuántos son quienes en Internet se ponen en escena y se contemplan en los comentarios elogiosos y gratificantes de los otros? "Una relación mediatizada por ordenador puede permitir a un individuo satisfacer de forma coherente la necesidad profundamente humana de tener relaciones con los otros y al mismo tiempo favorece en él el repliegue paranoide de evitar formas de involucramiento intersubjetivo" (Civin, 2003: 46-47). Porque la web ofrece una omnipotencia, y ella permite luchar con las angustias y las frustraciones. La conexión a Internet puede ser considerada como un cordón umbilical, que nutre y calma, enlazando un "gran todo" tranquilizador. De este modo, las nuevas tecnologías, en sentido amplio, se han convertido en el medio de placer preferido de las personas de 25 a 49 años, incluso antes que el sexo ${ }^{10}$.

Seguramente se ama aún "de verdad" en el 2014, incluso si la tentación es a veces grande de permanecer escondido detrás de la pantalla, en una postura todopoderosa. Continuaremos aún encontrándonos en la vida real, deseando los cuerpos, y forjando bellas historias IRL. De más en más, sin embargo, se utilizarán las TIC y sus providenciales recursos en un momento u otro del proceso amoroso. Así, más de la mitad de los encuentros amorosos de los treintañeros es producido por sitios que tienen precisamente esta finalidad ${ }^{11}$.

El modelo de pareja tradicional es puesto en cuestión por las TIC. Es cierto, Internet "produce" muchas parejas. Pero "desecha" también numerosas consecuencias, a medida que los "conquistadores/as digitales" se reconectan para adulterios digitales, polygaming y sexfriendi. Estos sitios dieron nacimiento a una sexualidad en banda ancha, muy recreativa. En paralelo, la sentimentalidad que producen estas redes digitales es lúdica y desinvolucrada; sin embargo, es cínica a la vez. Y violenta en muchos aspectos. Nuestra época es de un consumo sentimental y sexual de masa. Tomamos, disfrutamos, jugamos, rechazamos. No olvidemos las muy numerosas "bellas historias de la red". Pero sus actores confiesan que antes de poder constituirse en pareja, ellos conocieron decepciones y casi se rindieron, justamente a causa del cinismo ambiental y de la impresión desagradable de ser considerado como una mercancía en un supermercado, mientras ellos mismos se posicionaban en un inmenso catálogo de páginas llenas de personas para ser "consumidas".

No miramos todo esto con moralismo: no hay solo frustración y disgusto en el consumo sentimental y sexual industrializado por la red. Y son numerosas las personas que sienten mucho placer gracias a Internet; acumular aventuras, experimentar sexualmente, vivir de paréntesis sensuales gratificantes, rompiendo con la monotonía de sus vidas. Porque "en

\footnotetext{
9 Cabe señalar que net significa en inglés específicamente 'red' (fillet). En concordancia, la tela (toile) puede ser telaraña, y la red (réseau) nos evoca a la imagen del entramado de una malla o la trampa de redes.

10 Primer medio de placer: la high tech (39\%); el sexo (36\%) (Sondage Ipsos para Menstyle, citado por Télérama $\mathrm{n}^{\circ} 3072,26$ de noviembre de 2008).

11 Ibíd.
} 
línea" se seduce y se es seducido(a), y no se le debe rendir cuenta a (casi) nadie; la ligereza y el placer inmediato son los motores del sistema. Después de haber experimentado ad nauseam la primera posibilidad de los sitios de encuentros, el sexo, es probable que se siga el mismo movimiento pendular para hacer todo lo posible por conseguir la segunda promesa de estos sitios, que es su verdadera promesa comercial: encontrar el "amor verdadero".

Pero también se ha vuelto más complicado. Porque Internet estresa en vez de tranquilizar. Este casamentero tecnológico, en efecto, abrió una era de intercambiabilidad de las posibilidades amorosas. Es esto lo que las novelas y los testimonios consagrados a las relaciones en Internet señalan. Uno perdido, no más de diez, pero cien o miles encontrados, virtualmente, gracias a esto, que permiten las redes digitales, en términos de duplicación, pero también de duplicidad. ¿Cuántos son quienes tienen que jactarse de acumular decenas de aventuras, Ilevadas en paralelo, y centenares de relaciones one shot, acumuladas sobre la red? Porque "si la abundancia de posibilidades presenta un lado tranquilizador, ella puede igualmente involucrar una búsqueda indefinida, interminable, y zambullir a los internautas en una 'inquietud' en el sentido clásico del término, es decir, una búsqueda no solamente sin respuesta sino a la vez perpetuamente incierta en su objeto" (Parmentier, 2011: 174).

\subsection{Relaciones sentimentales frágiles e intercambiables}

Nosotros amamos en lo sucesivo con "contrato a plazo fijo". Pero la "pareja con contrato indefinido" también ha colapsado con la irrupción de las TIC. Ellas pueden en cualquier momento aceptar solicitudes inquietantes, o ser tentadas a "dar un paseo sobre la red", con toda discreción. Jamás se ha revisado tanto a los "ex" y a los amores de juventud, como en una época donde se puede encontrar a alguien en tan solo algunos segundos, con solo tres clics en un teclado.

De manera más general, Internet ha introducido en las parejas una soberana impaciencia, y especialmente en aquellas que se han formado con él. ¿Un pequeño defecto descubierto en el otro? ¿Un error? ¿Una disputa? ¿Un período un poco aburrido? La tentación es grande, conectarse con el fin de reactivar los pretendientes virtuales que sabrán ser "menos penosos". Sin embargo, esta es una ilusión que lleva a tomar lo imaginario por lo real. Es posible hablar de "bovarismo" en relación con Emma Bovary, la heroína de la novela francesa del siglo XIX de Gustave Flaubert, que había construido una vida quimérica por medio del poder de su imaginación.

No se deben considerar como recientes cosas antiguas. Así, hace un siglo, el célebre Marcel Proust, en su novela Abertine disparue12, evoca ya: "esta mujer única, sabemos que no era para nosotros, si hubiéramos estado en una ciudad distinta de donde nos encontramos, si hubiéramos andado en otros barrios, si hubiéramos asistido a otro salón. ¿Única como creemos? Ella es innombrable"... Y ¿cuántos están en la web para dar un toque a alguien, compartir el tiempo de un chat, de un café, de una copa juntos, de una salida, y jamás volver a ver a esta persona? En Internet, los romances se terminan todos los días antes incluso de

12 Albertine desaparecida o la Fugitiva. Una de las siete partes de la novela En búsqueda del tiempo perdido (N. del T.). 
haber sido vividos. Los solteros que flirtean "en línea" tienen esta conciencia difusa, de haberse cruzado con muchas personas con quienes una bella historia de amor hubiera sido posible. Multiplicado por millones, esta sensación probablemente contribuye en hacer nostálgica la generación de los "amantes de Internet", desilusionados por la violencia de las relaciones tecnificadas y liberalizadas, frente a tanto fracaso amoroso, delante de la fragilidad de los lazos y de la dificultad para construir una pareja sólida, en esta sociedad del "individualismo conectado".

\subsection{Un romanticismo de ahora en adelante tecnológicamente asistido}

Es siempre útil retornar a la sabiduría de los antiguos en períodos de confusión. Del Arte de amar de Ovidio, manual de "conquista" distendido, al Banquete de Platón y su bello origen de las relaciones fusionales, el amor vacila, eligiendo uno u otro, dependiendo si la época los autoriza más o menos. Internet y sus sitios de encuentros permiten optar por el modelo sentimental-sexual de la "intercambiabilidad" y de la aventura, pero por un tiempo solamente.

Porque a pesar de que hay cinismo o desilusiones, muchos internautas solteros guardan la intuición que una persona única está escondida justo detrás de la pantalla, y que serán al fin puestos en contacto, como los andróginos de Platón. Y se percibe finalmente, entonces, que la ideología liberal presente en los sitios de encuentro es contrabalanceada por una ideología romántica que ejerce su influencia desde hace ya largo tiempo.

\section{A MODO DE CONCLUSIÓN}

En el 2014, las y los que buscan el amor intentan atrapar a Venus o Cupido, figuras mitológicas del deseo y del amor, gracias a Internet. Estos aceptan a veces ofrecer este amor a aquellos que lo buscan con tanto método y constancia. En seguida, son los enamorados de la red quienes deben aprender a relacionarse, hasta convertirse en una "pareja verdadera". Lo más difícil comienza ahora. Porque Internet, que permite enlazar, es rápida para desatar. Y la historia de las relaciones amorosas jamás termina: siempre reinventándose, continúa escribiéndose.

\section{BIBLIOGRAFÍA}

Civin, M. (2003): Psychanalyse du Net, Hachette, Paris.

Illouz, E. (2006): Les Sentiments du capitalisme, Seuil, Paris.

Kaufmann, J.C. (2010): Sex@mour, Armand Colin, Paris.

Lardellier, P. (2004): Le coeur Net. Célibat et amours sur le Web, Belin, Paris.

(2012) Les réseaux du coeur. Sexe, amour et séduction sur Internet, Francois Bourin Editeur, Paris.

Parmentier, M. (2011): "Philosophie des sites de recontre", Hermès, 56.

Recibido: 17-05-2014

Aceptado: 01-07-2014 
